\title{
Benign Salivary Gland Neoplasm
}

National Cancer Institute

\section{Source}

National Cancer Institute. Benign Salivary Gland Neoplasm. NCI Thesaurus. Code C4600.

A non-metastasizing neoplasm that arises from the major or minor salivary glands.

Representative examples include Warthin tumor, monomorphic adenoma, and pleomorphic adenoma. 